\title{
AN APPROACH FOR RESIDUAL STRESS DETERMINATION BY MECHANICAL INDENTATION TECHNIQUE
}

\author{
Ondřej BÍLEK, MSc. Ph.D., Imrich LUKOVICS, prof. MSc. Ph.D., \\ David SÁMEK, MSc. Ph.D., Jana KNEDLOVÁ, MSc. \\ Department of Production Engineering, Faculty of Technology, Tomas Bata University in Zlin, \\ Nam. TGM 5555, 76001 ZLIN, Czech Republic
}

Keywords: Residual Stress, Mechanical Measurement, Plastics, FEM

\begin{abstract}
Residual stresses lower the utility value of plastic parts. Determination of the induced stresses can help deal with them. Measurements are time-consuming and expensive. A new approach to measuring residual stresses, such as indentation measurement, can lead to the simple determination of residual stresses. The paper shows the relationship between the condition of injection moulding, the subsequent residual stress, and hardness through thickness. The computer model displays the field and magnitude of residual stress in the samples. The model results are then compared to measured parameters after indentation and the magnitude of residual stress determined by the standard hole drilling method.
\end{abstract}

\section{INTRODUCTION}

The structure of plastic parts are significantly influenced by their internal residual stresses. Their nature and magnitude is a function of the technological process used and the subsequent treatment. Residual stresses in various materials are responsible for lowering product quality.

Thermoplastic polymer mouldings contain residual stresses that result from different cooling rates throughout the thickness of the mould. Although these stresses are commonly found in plastics, their magnitude can be extremely difficult to predict as they depends upon a wide range of variables, including the mould design, material and processing parameters. Rapid cooling of the plastic during injection moulding typically inhibits the material from reaching its equilibrium configuration resulting in residual stresses becoming trapped in the material. These stresses can significantly reduce the life expectancy of the product [1, 8], increasing the likelihood of dimensional instability and environment stress cracking.

The design of a moulded plastic part greatly influence its stability and internal stresses. Nevertheless, it cannot fully remove residual stresses from the parts due to the complex nature of the injection process. Therefore it is important to identify the character of induced stresses in the part.

Measurements of the induced residual stresses can identify their magnitude and location. Photoelasticity is a simple method for testing transparent materials; other techniques destroy the measured part $[3,6,10]$. A more sophisticated method is the hole-drilling technique, which quantifies the deformation of the sample while drilling a hole, and the corresponding stress is calculated from the deformation. An alternative method [2, 9], known as the layer removal technique, is similar to the hole-drilling, and chemical investigation methods. 
The hole-drilling method relies on stress relaxation when a hole is drilled into the center of a rosette strain gauge. When the material is removed by drilling, the extent of the strain relief is caught by the gauges and the direction and magnitude of the principal stresses can be calculated. This method has many advantages, but it also has disadvantages, particularly in the fact that a rosette is oriented regardless of the direction of principal stress and thus, have to be considered as unknown parameters before drilling the hole. Another drawback is an availability of some distance between the edge of hole and measurement points where the strain gauges are attached. This fact reduces the sensitivity of the technique because the greatest response of residual stress corresponds to the boundary of the hole.

All the methods mentioned above are expensive and time consuming. Predicting internal stresses induced during injection can be also done by a computer model. This approach is capable of adjusting process parameters to lower residual stresses in the injected part.

The relationship between hardness and other parameters has been investigated only by a few researchers. Currently, the dependence of hardness on residual stress has become a useful tool in determining the process conditions, which is the preferred topic of studies.

Hence, the connection between the invisible (but existing) residual stress inside injection-moulded parts and the macroscopic interference of the structure, are growing in interest. No studies so far have observed the influence of classical variables on the internal stresses. Clarifying the relationship between residual stress and the macroscopic changes is currently the objective to achieve.

The following study should contribute to the solution of problems of measuring residual stresses. In addition, the low cost measurement of hardness should substitute current techniques for the determination of residual stresses.

\section{METHODS}

In order to investigate the origin of residual stresses in injection moulded products a series of tests were performed to determine the dependence of the stresses on the process conditions.

The injected sample was a $3 \mathrm{~mm}$ thick square plate, where melt was injected from the corner. Moreover, samples were injected under different conditions, as shown in Table 1. The samples were packed at high and low pressure. The material used for the experiment was polymethylethacrylate (trade-name Sebena). Samples were prepared on the DEMAG ERGOtech 50 injection moulding machine.

Table 1: Conditions of injection moulding

\begin{tabular}{|l|l|l|}
\hline Sample designation & Injection pressure (bar) & Injection speed (mm/s) \\
\hline I & 80 & 140 \\
\hline II & 50 & 120 \\
\hline
\end{tabular}

A computer model of the injection process was created. The model $[4,5,7]$ was used to determine dependencies and magnitude of residual stresses which arise in the sample during 
injection. This was simulated in the computer program: MoldFlow Plastics Insight. The simulated conditions were the same as the real experiment.
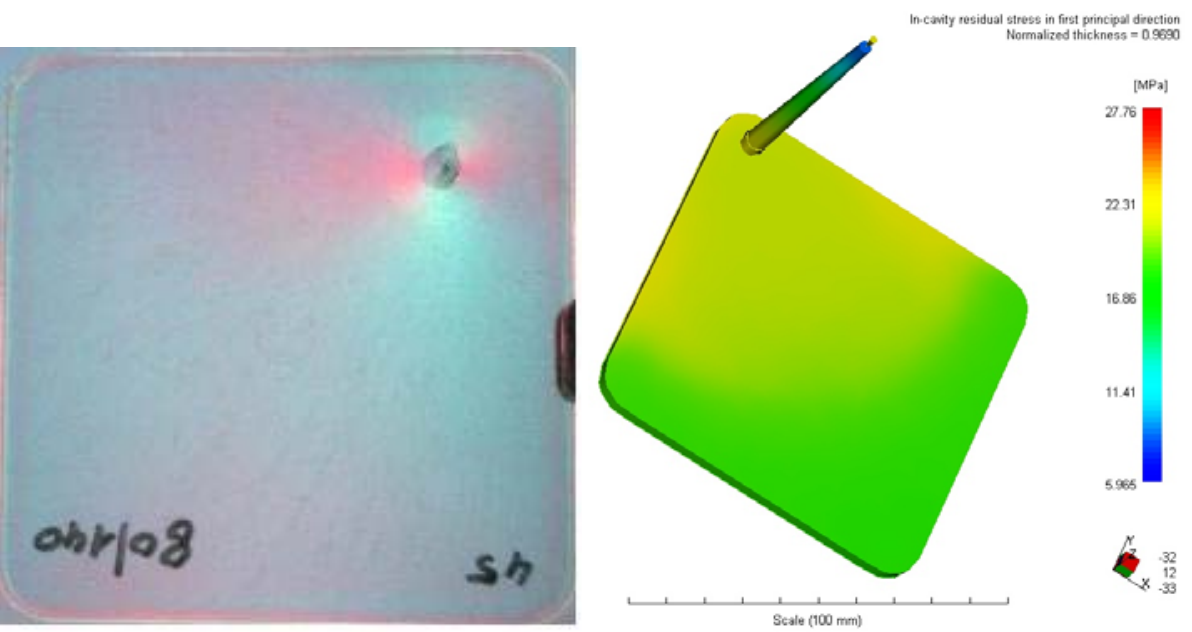

Figure 1: Photoelasticity observation for sample type I and computer model of residual stress

Next, photoelastic measurements were carried out to confirm the existence of residual stresses in prepared samples. Besides revealing the presence of residual stress, the photoelasticity method shows the development of residual stresses in the observed plane.

The magnitude of residual stresses in the sample was compared to the computer model provided by the hole the drilling method. The treatment took place at the University of Technology in Brno, Faculty of mechanical engineering. The HBM-1.5/120RY61S Experimental strain gauge rosette was used. Output stress curves were interpolated from the measured strain. The diameter of the hole was $2.98 \mathrm{~mm}$ and the endmill diameter was $1.8 \mathrm{~mm}$. Measurements were run in 10 steps.

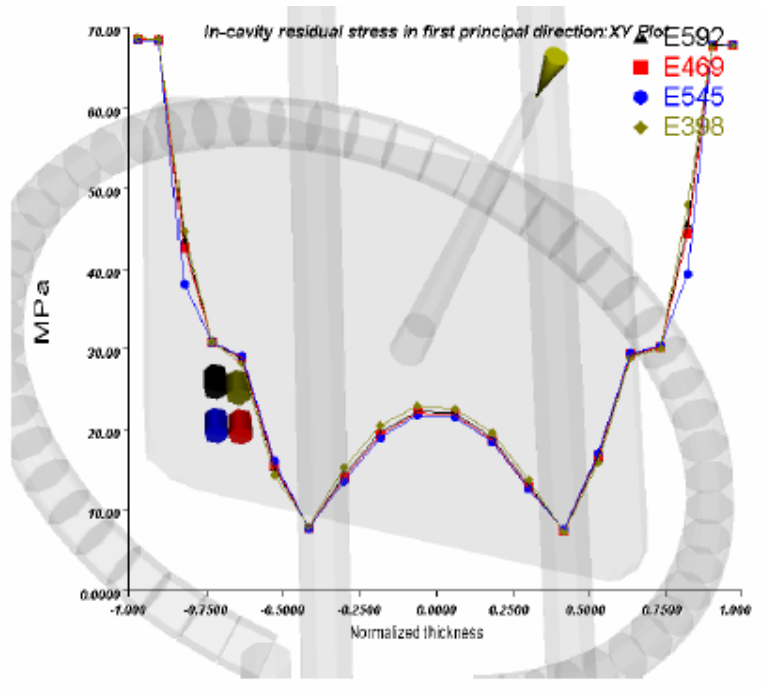

Figure 2: Comparison of residual stress for close points 
For the purposes of this study, a relationship between hardness and internal residual stresses through the thickness of the sample is assumed. Therefore samples were milled on the FC $16 \mathrm{CNC} / \mathrm{PC}$ milling machine, and the Shore hardness " $\mathrm{D}$ " was measured on Bareiss HPE-D, DGM 9318389.5 in accordance to the ISO 868 standard. For statistical purposes, all measurements were repeated 10 times. Injection dependencies were observed as a change of hardness, and thereby residual stress held in the sample. As a new technique, no literature reviews can be found to prove the fact that hardness may be affected by residual stresses.

\section{EXPERIMENTAL RESULTS}

Photoelasticity measurements exhibited the presence of residual stresses in the prepared samples, as can be seen from the color palette in Fig. 1. Higher color intensity can be seen around the injection gate. With different injection conditions, the color differs only in the intensity. Nevertheless, the location of residual stresses is the same. In general practice, residual stresses grow with increasing injection pressure, which was verified in this experiment.

In comparison to the computer model (Fig. 1 right) only small differences can be found. The computer model represents the ideal state of the process, without any influence of real environmental changes. But, as indicated in the aforementioned figure, residual stresses are markedly higher at the gate than in other parts of the sample. The real sample is a result of thermal fluctuation and subsequent relaxation, so the field of relaxation stresses is more complicated.

The computer model displays an ideal stress distribution in the cross-section of the sample. Specific residual stress development differs slightly, as can be seen in Fig. 2. Points in the picture, marked E592, E469, E545 and E398 signify that elements of the sample and curves show a development of residual stresses throughout the $3 \mathrm{~mm}$ thickness.

Larger differences in residual stress behavior throughout the cross-section of the samples was observed when packing was carried out at high and low pressures. High injection pressures create a larger variation in residual stresses (Fig. 3). Thus low injection pressure gives slight variations in the induced residual stress which are about ten times smaller than injecting at high pressure; compare graphs in figure 3.
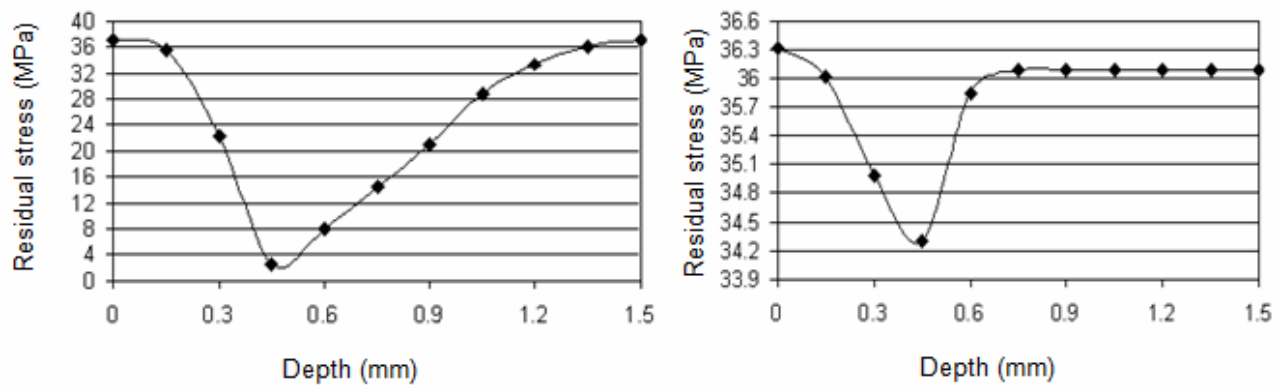

Figure 3: In-cavity induced residual stress at high injection pressure (left) and low injection pressure (right)

The residual stress, obtained from the hole drilling method, correspond to the computer model of in-cavity residual stress (Fig. 4.). The Behavior had the same lowering character to a 
depth of $0,4 \mathrm{~mm}$. Measurements recorded a deviation of residual stress at $0,05 \mathrm{~mm}$, not detected by the computer model, due to low resolution.

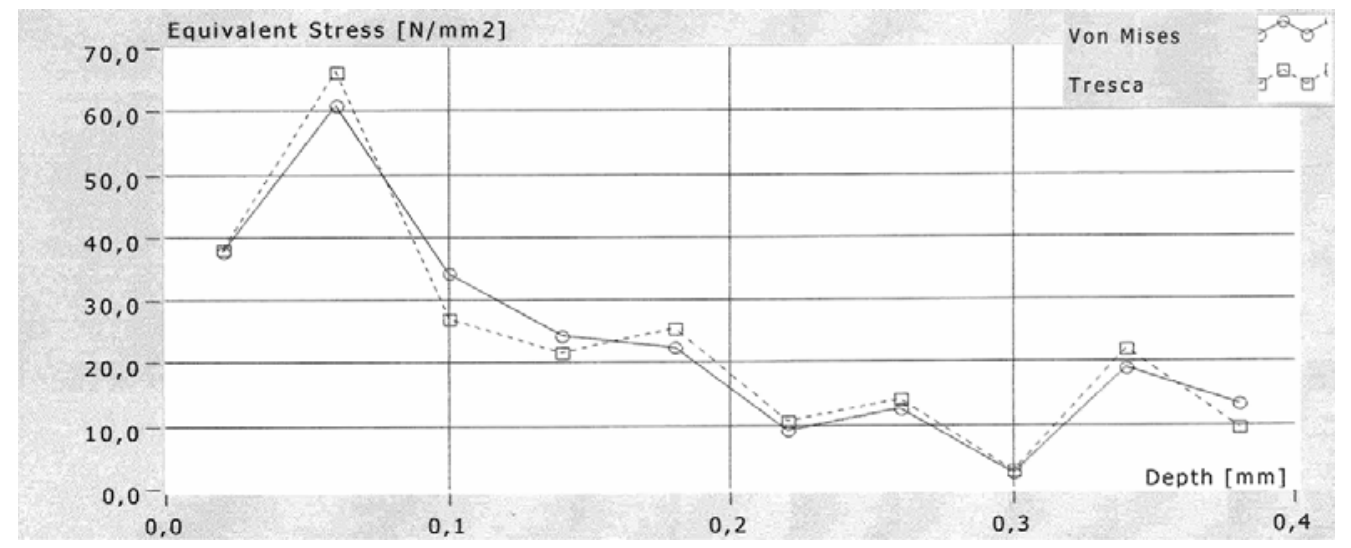

Figure 4: Residual stress evaluation using hole drilling method

Besides the presence of residual stresses in the prepared samples, the way they interact with the hardness was also investigated. The data from the computer model was compared with the values of hardness measured at a specific depth. The samples with induced stresses showed variations in hardness. Fig. 5 shows the dependence of residual stresses and hardness related to the cross-section of the sample. The curves describe the values, in the same area, of stresses in the computer model and hardness in the real samples. As can be seen, in this case, hardness remained at the same level, only a small decline could be observed after the lowest peak as a response to changing residual stress distribution.

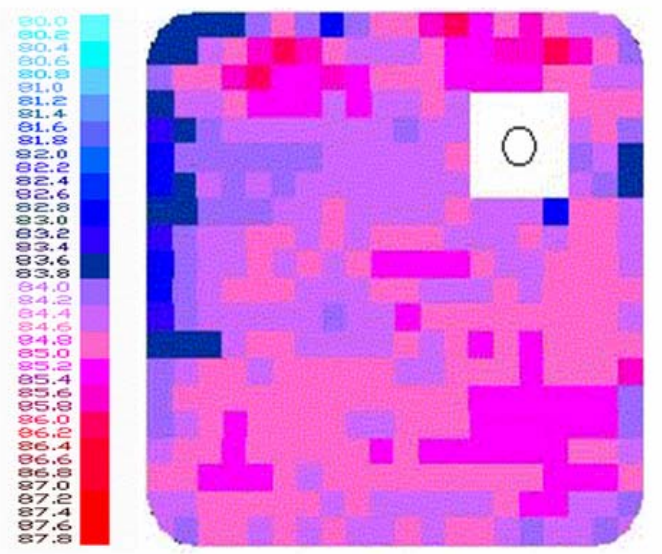

Figure 5: Surface measurement of hardness for sample type I

Measurements of hardness on the surface of the samples showed considerable dependencies on the position. The area of measurement included the whole surface of the sample, 
except for the injection gate. This can lead to the conclusion, that cutting a groove for measuring hardness affected the measurement results.

\section{CONCLUSIONS}

The relationship between residual stresses and hardness is not an extensive assessment. Values of residual stress obtained from hole drilling method had approximately the same progression. The magnitude varied due to the relaxation of polymer sample with time. Hence data from computer model was used. Even though the field of residual stresses of the computer model was in agreement with the observed residual stresses, the measured hardness throughout the thickness varied. The high magnitude of the presented residual stress results in a higher value of hardness, the same way as low magnitudes cause lower hardness. Nevertheless, the differences are small and approximately follow the standard deviation. The relationship between residual stresses and hardness is inconclusive in regard to the measurement method. Substituting hardness measurement by micro hardness is a way to improve accuracy. This study should be taken as a preliminary study. Further research in this area might lead to new and cheap methods of residual stress measurement.

\section{REFERENCES}

[1] ÉLESZTÖS, P. Thermal Stresses at the Extrusion of an Infinite Cylinder, International Journal of Mechanics and Solids (IJM\&S), Vol. 1, No. 1, March 2006.

[2] KAMAL, M. R., et al. Residual thermal stresses in injection moldings of thermoplastics: A theoretical and experimental study. Polymer engineering and science, May 2002, Vol. 42, no. 5, pp. 1098-1114.

[3] KANDIL, F. A. A Review of Residual Stress Measurement Methods - A Guide to Technique Selection. NPL materials centre, February 2001, NPL Report MATC(A)04.

[4] MA, YC., YHOU, Z. C., LONG, S. G., LU, C. Residual Stress Effect on Hardness and Yield Strength of Ni Thin Film. Surface \& Coatings Technology, vol. 207, pp 305-309, 2012.

[5] MAXWELL, A. S., TURNBULL A. Measurement of Residual Stress in Polymeric Materials. Centre for Materials Measurement and Technology, National Physical Laboratory, Teddington, 2002.

[6] STAS, O., TOLNAY, M., MAGDOLEN, L. Application of Artificial Intelligence in Manufacturing Systems. Mechanical and Electronics Engineering. ICMEE 2009 : Proceedings of the 2009 international

[7] SUBA O., SYKOROVA L., MALACHOVA M., SAMEK D. Modeling of Transient Thermal Stress in Layered Walls. Manufacturing Technology. X, 2010 ISSN 1213-2489.

[8] TURNBULL, A. Residual Stress in Polymers - Evaluation of Measurement Techniques. Journal of materials science 34, 1999, pp. 451-459.

[9] TREBUNA, F., SIMCAK, F., SARGA, P., TREBUNA, P. Residual Stresses and Problems Connected with their Verification. Experimentalni Analyza Napeti 2009/Experimental Stress Analysis, Proceedings. Pp 259-262, 2009.

[10] ZHANG, X., CHENG, X., STELSON, K. A. Approximate Model of Thermal Residual Stress in an Injection Molded Part. Journal of Thermal Stresses. Vol. 25 (6), pp. 523-538, 2002. 